\title{
Redox homeostasis in plants under abiotic stress: role of electron carriers, energy metabolism mediators and proteinaceous thiols
}

\author{
Dhriti Kapoor*, Resham Sharma, Neha Handa, Harpreet Kaur, Amandeep Rattan, Poonam Yadav, \\ Vandana Gautam, Ravdeep Kaur and Renu Bhardwaj
}

Botanical and Environmental Sciences, Guru Nanak Dev University, Amritsar, India

\section{Edited by:}

Nafees Ahmad Khan, Aligarh

Muslim University, India

Reviewed by:

Mohammad Mobin, University of

Tabuk, Saudi Arabia

Noushina Iqbal, Aligarh Muslim

University, India

*Correspondence:

Dhriti Kapoor, Botanical and

Environmental Sciences, Guru

Nanak Dev University,

Amritsar-Punjab, 143005 Amritsar,

India

e-mail: renubhardwaj82@gmail.com
Contemporaneous presence of both oxidized and reduced forms of electron carriers is mandatory in efficient flux by plant electron transport cascades. This requirement is considered as redox poising that involves the movement of electron from multiple sites in respiratory and photosynthetic electron transport chains to molecular oxygen. This flux triggers the formation of superoxide, consequently give rise to other reactive oxygen species (ROS) under adverse environmental conditions like drought, high, or low temperature, heavy metal stress etc...that plants owing during their life span. Plant cells synthesize ascorbate, an additional hydrophilic redox buffer, which protect the plants against oxidative challenge. Large pools of antioxidants also preside over the redox homeostasis. Besides, tocopherol is a liposoluble redox buffer, which efficiently scavenges the ROS like singlet oxygen. In addition, proteinaceous thiol members such as thioredoxin, peroxiredoxin, and glutaredoxin, electron carriers and energy metabolism mediators phosphorylated (NADP) and non-phosphorylated $\left(N A D^{+}\right)$coenzyme forms interact with ROS, metabolize and maintain redox homeostasis.

Keywords: abiotic stress, reactive oxygen species, ascorbate, tocopherol, glutathione

\section{INTRODUCTION}

During cellular respiration, the accretion of molecular oxygen $\left(\mathrm{O}_{2}\right)$ in earth's environment allows aerobic organisms to utilize $\mathrm{O}_{2}$ as the terminal electron acceptor that gives a higher amount of energy than fermentation (Dismukes et al., 2001). $\mathrm{O}_{2}$ gives rise to prolific reactive excited states, like reactive oxygen species (ROS) and their derivatives during normal metabolic activity as a consequence of various environmental perturbations (Scandalios, 2005). ROS is a product of cellular metabolism; however, the balance between the generation and removal of ROS is disturbed in cellular components of plants under stress conditions (Karuppanapandian et al., 2011). ROS like hydroxyl radical $\left(\mathrm{OH}^{-}\right)$, superoxide radical $\left(\mathrm{O}_{2}^{-}\right)$, hydrogen peroxide $\left(\mathrm{H}_{2} \mathrm{O}_{2}\right)$, hydroperoxyl radical $\left(\mathrm{HO}_{2}\right)$, alkoxy radical (RO'), peroxy radical (ROO'), singlet oxygen $\left({ }^{1} \mathrm{O}_{2}\right)$ and excited carbonyl (RO*), are cytotoxic to plants (Vellosillo et al., 2010). Attack of ROS may results in serious damage to cellular components, DNA lesions and mutations and this frequently leads to irretrievable metabolic dysfunction and cell death (Karuppanapandian et al., 2011). ROS are scavenged by various antioxidative defense systems under steady state conditions (Navrot et al., 2007).

Overproduction of ROS in plants is induced by various environmental perturbations like drought, heat, high light intensity (HL), salinity, chilling, herbicides, heavy metals, pathogens, wounding, ozone $\left(\mathrm{O}_{3}\right)$, atmospheric pollutants, and photosensitizing toxins which causes oxidative cellular damage
(Karuppanapandian and Manoharan, 2008; Mafakheri et al., 2010). Reduction of a single electron from $\mathrm{O}_{2}$ results in the production of the superoxide radicals $\left(\mathrm{O}_{2}^{--}\right)$, which is quite reactive. Consequently, it cannot cross biomembranes and may readily dismutated to $\mathrm{H}_{2} \mathrm{O}_{2}$. $\mathrm{O}_{2}^{--}$also react with $\mathrm{NO}$, another very dominant signaling free radical species that gives rise to peroxynitrite $\left(\mathrm{OONO}^{-}\right) . \mathrm{O}_{2}^{--}$leads to the formation of $\mathrm{HO}_{2}$ by protonation in aqueous solutions that can cross biomembranes and subtract hydrogen atoms from polyunsaturated fatty acids (PUFAs) and lipid hydroperoxides, therefore initiating lipid autooxidation (Halliwell and Gutteridge, 2000). $\mathrm{H}_{2} \mathrm{O}_{2}$ is a relatively long-lived molecule and moderately reactive, which can disseminate short distances away from its production site. $\mathrm{H}_{2} \mathrm{O}_{2}$ causes inactivation of enzymes by oxidizing their thiol groups. $\mathrm{H}_{2} \mathrm{O}_{2}$ enables it to diffuse the damage and also act as a messenger in the stress signaling response and thus can travel freely across membranes (Moller et al., 2007). It may also trigger the production of $\mathrm{OH}^{\prime}$, the most reactive oxidant in the ROS family and also considered as one of initiation radicals for lipid peroxidation, via Haber-Weiss/Fenton reactions that utilize the suitable transition metals, especially, iron (Fe) (Lee et al., 2007). The products of $\mathrm{OH}^{\text {- }}$ reactions may extract signaling responses and cells sequester the catalytic metals to metallochaperones efficiently avoiding $\mathrm{OH}^{-}$, though it does not have signaling function (Moller et al., 2007). It can potentially react with all biomolecules like, proteins, lipids, pigments and DNA and almost all constituent of cells. Excess production of ROS leads to programmed cell death (PCD), as plant 
cells are not capable to scavenge these ROS (Manoharan et al., 2005).

\section{CONCEPT OF REDOX HOMEOSTASIS}

Contemporaneous presence of both oxidized and reduced forms of electron carriers are required by competent flux through electron transport cascades of plant. In photosynthetic and respiratory electron transport chains, the requirement of regular flux of electrons to molecular oxygen from multiple sites is known as redox poising. Despite specific oxidases catalyze the specialized water producing reactions. Primary product of this flux is superoxide and other ROS are produced consequently. Superoxide or $\mathrm{H}_{2} \mathrm{O}_{2}$ are generated by various enzyme systems. Due to the reactive nature of these intermediates they are able to act as signaling molecules; therefore their accumulation must be regulated. Accumulation of ROS is resoluted by the antioxidative system, which further balance the metabolism of organism by maintaining the proteins and other cellular components in an active state (Foyer et al., 2005). Large pools of these antioxidants govern the redox homeostasis, which absorb the reductants and oxidants. ROS signaling pathways are generated by homeostatic regulation that is achieved by antioxidant redox buffering. Antioxidants determine the lifetime and the specificity of the ROS signal. Generation of superoxide, $\mathrm{H}_{2} \mathrm{O}_{2}$ and even singlet oxygen are coped by plant cells (Wagner et al., 2004). Moreover, due to signaled induction of other defense systems, plants adapt very well for the depletion of antioxidants. Cytoplasmic thiols in the reduced state are balanced in the plants because of the low thioldisulfide redox potential, which is imposed by the thiol buffer, glutathione. Though, plant cells make an additional hydrophilic redox buffer namely ascorbate (vitamin C), which provides strong protection against oxidative damage. However, plants also synthesize tocopherols (vitamin E) that perform as key liposoluble redox buffers. Tocopherol is considered as an effective scavenger of other ROS including singlet oxygen species and in this case the reduced scavenging form is regenerated by ascorbate (Foyer et al., 2005). Moreover, it raises the array of efficient superoxide scavenging as the tocopherol redox couple acts as affirmative midpoint potential than that of the ascorbate pool. In plant cells, the capability of glutathione, tocopherol and ascorbate pools to act as redox buffers is one of significant attributes. Low activities of ascorbate peroxidase and catalase in plants show less harsh symptoms of stress than those plants which lack either one of these enzymes (Rizhsky et al., 2002). For example, tocopherol-deficient Arabidopsis vte mutant seedlings possess large amounts of lipid peroxides, whereas mature plants show slightly abnormal phenotype (Kanwischer et al., 2005). It is estimated that DNA repair and rapid protein turnover is enhanced to recompense for improved oxidation or loss of antioxidants.

\section{ROLE OF REDOX-HOMEOSTASIS MANAGERS AGAINST VARIOUS ABIOTIC STRESSES \\ ASCORBATE}

Ascorbate (L- Ascorbic Acid/Vitamin C/AsA), a water soluble antioxidant of universal distribution in higher plants, has been studied for its biosynthesis, localization and presence within plant cells, metabolic involvement and biochemistry with respect to other antioxidants (Khan et al., 2011; Szarka et al., 2012; Gallie, 2013; Lisko et al., 2014; Venkatesh and Park, 2014; Foyer, 2015). AsA is concentrated in photosynthetic tissues, meristematic tissues, flowers, young fruits, root tips etc... (Gest et al., 2013). The AsA biosynthetic pathway considers D-mannose and L- galactose as primary substrates through various enzymatic reactions (Müller-Moulé, 2008). In addition to this being the main scheme of ascorbate generation (Smirnoff-Wheeler pathway), three other pathways namely the L-gulose (Gul) shunt, the D-galacturonate (GalU) pathway, and the myo-inositol (MI) route have also been identified in plants (Venkatesh and Park, 2014). AsA is generated on the inner mitochondrial membrane; and further transported to different cellular components including the apoplast for consumption, degeneration, and recycling (Green and Fry, 2005) (Figure 1). Its transport within the plant system is mediated by facilitated diffusion or active transport systems (Ishikawa et al., 2006). Since this is such a ubiquitous antioxidant present in plant system, it plays a wide array of roles such as scavenging of deleterious ROS produced during all sorts of abiotic and biotic stress (Teixeira et al., 2004), central role in photosynthesis (Smirnoff, 1996), as a major participant in detoxification mechanisms focused in chloroplasts such as the water-water cycle-WWC or the Mehler peroxidase reaction (Neubauer and Yamamoto, 1992) and the xanthophyll cycle (Yabuta et al., 2007).

The hydrogen peroxide and superoxide radicals generated in this reaction are reduced to water by AsA in the presence of ascorbate peroxidase (APX). MDA is a by-product released in this reaction and is further converted to ascorbate either by reduced ferredoxin of PSI (photosystem I) or by MDHA reductase using NADH or NADPH as electron donor (Sano et al., 2005). AsA has also been identified as an alternative electron donor of PSII; thereby retarding the photo inactivation and ROS activity in the thylakoid and providing protection to the entire photosynthetic machinery (Tóth et al., 2011; Gururani et al., 2012). In addition to all this, AsA participates in the regeneration of vitamin $E$ and acts as a substrate for synthesis of important organic acids such as; L-glyceric, L-oxalic acids, L-tartaric, and L-threonic acid (Debolt et al., 2007). AsA however plays the most important

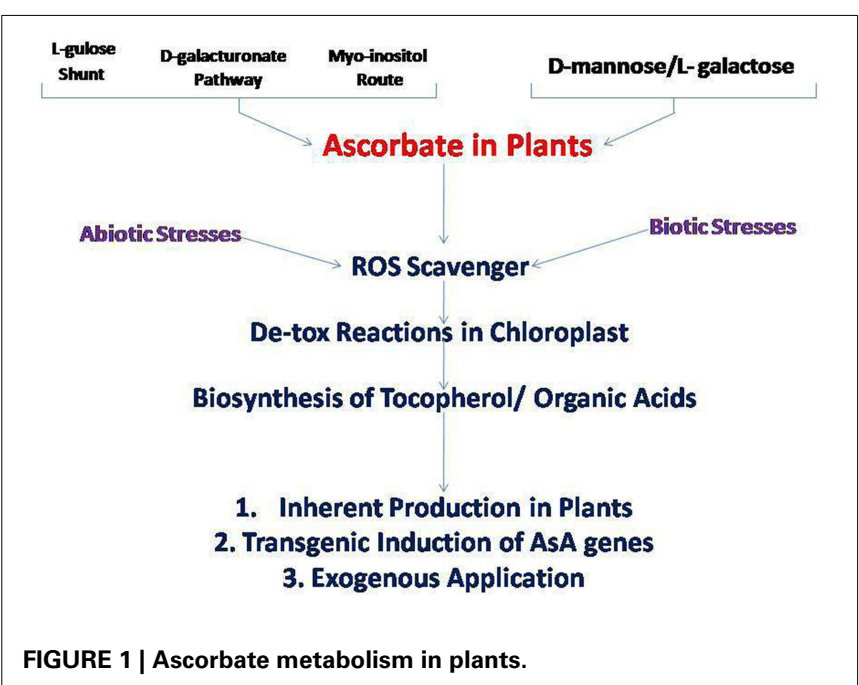


role of guarding cells and organelles against oxidative damage by eliminating ROS which are produced by aerobic metabolic processes such as photosynthesis and respiration or by environmental stresses like salt, drought, cold, and excess light; hence becoming an imperative molecule for overall plant health and well-being. Although there are many experimental and factual evidences from various mutant and transgenic studies for the same, here we discuss the relevant ones with special reference to abiotic stresses. Elevated AsA levels and induction of cytosolic APX have been reported in plants subjected to high light oxidative stress (Yabuta et al., 2007). Many cytosolic and chloroplast centered APX genes have been identified in Arabidopsis spp, Oryza spp ,Lycopersican spp. etc... (Koussevitzky et al., 2008; Najami et al., 2008; Lazzarotto et al., 2011; Pang et al., 2011). Similarly, plants under water deficit stress also over produce ascorbate to counter fall of physiological parameters and plant survival (Dolatabadian et al., 2009). Sesame seeds coated with AsA-PEG were subjected to drought stress and surprisingly, recorded for a good germination percentage and index, dry weight and seedling length (Tabatabaei and Naghibalghora, 2013). Another stress countered by AsA is the ozone stress resulting from industrial activities causing extensive leaf damage, fallen stomatal conductance and photosynthesis rates in plants (Sanmartin et al., 2003). The ROS accumulation caused due to ozone entering the apoplastic and symplastic components through stomata leads to severe damage to the photosynthetic machinery (Cho et al., 2011). Apoplastic AsA forms the primal barrier against this stress by direct reaction with free radicals formed by ozone (Chen and Gallie, 2005). Ozone resistant plant species showed enhanced apoplastic ascorbate levels (Feng et al., 2010). Exogenously applied AsA prevented chances of foliar injury and checked loss of photosynthetic activity caused by ozone stress (Zheng et al., 2000; Maddison et al., 2002). Similarly, plants with over expressing DHAR genes also showed an increased ozone tolerance and higher level of photosynthetic activity (Chen and Gallie, 2005). ROS generated due to high/low temperature is also well balanced by AsA metabolic responses in many transgenic plants such as potato, tomato, rice, etc... (Tang et al., 2006; Sato et al., 2011). Increased tolerance to temperature stress was also observed in transgenic tobacco plants over expressing the thylakoid-bound APX gene from tomato (Sun et al., 2010). During chilling and heat stresses, the photochemical/oxidative efficiency of PSII in the transgenic lines was observed to be higher than that of non-transformed/wild-type plants (Wang et al., 2011), Arabidopsis spp. despite showing a small increase in Asc content, over expressed rice DHAR gene and showed more salt tolerance (Ushimaru et al., 2006). Tomato seedlings over expressing a chloroplast-targeted tomato MDHAR gene reduced membrane damage and resulted in a higher net photosynthetic rate, higher maximal PSII photochemical efficiency and increased fresh weight when subjected to low or high temperatures ( $\mathrm{Li}$ et al., 2010). The role of AsA in countering metal stress is well confirmed by transgenic and mutant studies. AsA and related enzymes such as DHAR have been expressed by genes from Arabidopsis in tobacco for inducing greater tolerance to aluminum and thus resulting in elevated AsA concentration in roots after exposure to Al toxicity (Yin et al., 2010). Similarly, coexpression of a Cu-Zn SOD and APX gene lead to an enhanced tolerance to metal and salt stress localized within the chloroplast of tobacco transgene constructs (Lee et al., 2007; Le Martret et al., 2011), indicating that the beneficial effect of increasing DHAR expression can be used in a combinatorial approach with other enzymes involved in oxidative stress. The adverse effects of $\mathrm{Cu}$ toxicity treatments on root and shoot growth was partially alleviated by the treatment of test plants with AsA, thiamine (vitamin B1) and salicylic acid (Al-Hakimi and Hamada, 2011).

\section{GLUTATHIONE}

Glutathione (GSH), a low molecular weight thiol $(\gamma$ glutamylcysteinylglycine) is one of the most important metabolites of the living systems (Gill and Tuteja, 2010; Noctor et al., 2012). It has a vital role in sulfur metabolism and translocation (Hell, 1997). It is also reported to play a significant role in cellular metabolism and as a reductant in scavenging of radicals in intracellular environment (Gill and Tuteja, 2010). GSH also functions as reactive nucleophiles which help in detoxification of toxins of electrophilic nature. It is also reported to have signaling function which responds to changes in extracellular environment and is known for its role in regulation of gene expression (Sanchez-Fernandez et al., 1997). It is also involved in synthesis of phytochelatins in which it acts a precursor and aids in binding heavy metals (Grill et al., 1989).

Biosynthesis of GSH occurs in two step process. In first reaction, L-glutamate and L-cysteine are converted to $\gamma$-glutamylcysteine $(\gamma$-EC) with the help of enzyme $\gamma$ glutamylcysteine synthase ( $\gamma$-ECS). $\gamma$-EC is further converted to GSH by addition of glycine by enzyme glutathione synthase (Figure 2). Both these reactions are carried in the presence of ATP (Meister, 1988). Inside the cell, GSH is localized usually

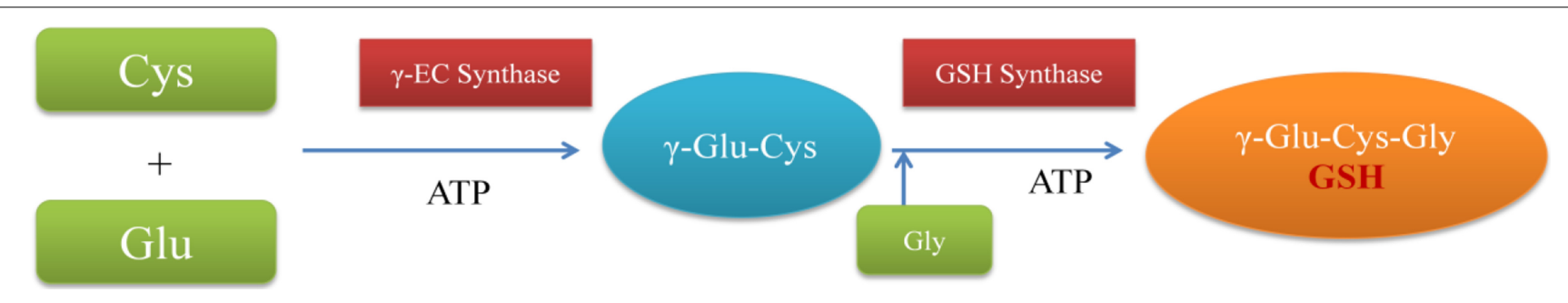

FIGURE 2 | Schematic representation of GSH biosynthesis. Cys, L-cysteine; Glu, L-glutamate; $\gamma$-Glu-Cys, $\gamma$-glutamylcysteine; $\gamma$-EC synthase, $\gamma$-glutamylcysteine synthase. 
in cytoplasm, endoplasmic reticulum, vacuoles, mitochondria, chloroplasts and peroxisomes (Mittler and Zilinskas, 1992; Jimenez et al., 1998). In cellular environment, glutathione is mainly present in reduced state. Hence, oxidized form of glutathione (GSSG) is present in very low proportions. Therefore, under optimum conditions, a high GSH:GSSG ratio is maintained (Mhamdi et al., 2010; Noctor et al., 2011). In stressed conditions, GSH along with ascorbate (AsA) plays a central role in scavenging of ROS.

Many studies have indicated a correlation between levels of $\mathrm{H}_{2} \mathrm{O}_{2}$ and glutathione (Noctor et al., 2012). $\mathrm{H}_{2} \mathrm{O}_{2}$ metabolism via GSH involves three types of peroxidases which are ascorbate peroxidase (APOX), peroxiredoxin (PRX) and glutathioneS-transferases (GSTs). APOX is a class I heme based peroxidase and is specific to $\mathrm{H}_{2} \mathrm{O}_{2}$. It is involved in AsA-GSH radical scavenging pathway that uses NADPH to reduce $\mathrm{H}_{2} \mathrm{O}_{2}$ via AsA-GSH pools (Noctor et al., 2012). In this process, APOX reduces $\mathrm{H}_{2} \mathrm{O}_{2}$ to $\mathrm{H}_{2} \mathrm{O}$ and AsA acts as a reductant which changes to monodehydroascobate (MDHA). MDHA is unstable and is converted to AsA in the presence of enzyme monodehydroascobate reductase (MDHAR) and NADPH. MDHA can also lead to the formation of dehydroascobate (DHA) which further gets reduced to AsA with the help of the enzyme dehydroascobate reductase (DHAR) (Winkler, 1992). The reductant is this case is GSH which gets oxidized to GSSG thereby indicating that GSH has an imperative role in maintaining AsA pool in the cellular environment (Noctor et al., 1998). GSSG is reduced back to GSH by glutathione reductase (GR) in presence of NADPH.

The second type of peroxidases i.e., peroxiredoxins (PRX) are thiol peroxidases which can reduce $\mathrm{H}_{2} \mathrm{O}_{2}$ as well as other peroxides thereby indicating their low specificity to $\mathrm{H}_{2} \mathrm{O}_{2}$ (Dietz, 2003; Tripathi et al., 2009). PRXs are of four types and out of these, PRX II uses GSH as a reductant while other three either use thioredoxin (TRX) or NADPH-thioredoxin reductase (NTR) (Pulido et al., 2010). Glutathione peroxidases (GPX) are also included in PRXs as they TRX-dependent peroxiredoxins (Iqbal et al., 2006; Navrot et al., 2006). In plants, GPXs are less likely to be involved in peroxide mediated oxidation of GSH and it is suggested that peroxidation could be carried out by GST (Wagner et al., 2002; Dixon et al., 2009). Many GSTs found in plants have been shown to possess GPX like activity. Type I and type III class of GSTs have been identified in many plants and have been reported to actively respond to oxidative stress (Dixon et al., 1998). Some other enzymes such as methionine sulphoxide reductase (MSR) are also reported to carry out ROS-stimulated oxidation of GSH (Tarrago et al., 2009). Hence, reduction of $\mathrm{H}_{2} \mathrm{O}_{2}$ and other peroxides by GSH occurs by both AsA-GSH radical scavenging pathway and AsA independent pathway (Figure 3).

One of the important roles of GSH is synthesis of phytochelatins. These are organic ligands that have the ability to bind heavy metals and then these metal complexes are transported to vacuole (Cobbett and Goldsbrough, 2002). Enzyme phytochelatin synthase (PCS) catalyzes the formation of phytochelatins either from GSH or homologous bithiols (Ha et al., 1999; Vatamaniuk et al., 1999). During increased concentrations of heavy metals, $\gamma$-glutamylcysteine moiety from one GSH molecule and glutamic acid from another GSH molecule are condensed by PCS thereby releasing glycine as residue and forming phytochelatin molecule which are then able to form metal complexes (Clemens, 2006). Hence, GSH and related enzymes play a crucial role in maintaining the homeostasis of cellular environment and protect the plant system from adverse effects of various stresses.

\section{TOCOPHEROL}

Tocopherol is found ubiquitously in the plant kingdom and occurs in all the plant parts. It plays a key role in signal transduction pathways and in the gene expression regulation in different processes such as plant defense and export of photoassimilates (Falk and Munne-Bosch, 2010). It acts as a key lipid soluble redox buffer. It is an important scavenger of singlet oxygen species and also scavenges other ROS (Foyer et al., 2005). Tocopherol role is important under the conditions of severe stress (Havaux et al., 2005) and when stress conditions are not severe, other antioxidants play their protective roles. Tocopherol antioxidant activity depends on its ability of donation of its phenolic hydrogen to free radicals. The $\alpha$-tocopherol has the highest antioxidant activity of all the tocopherol types, the $\delta$-tocopherol has the lowest and the $\beta$ - and $\gamma$-tocopherols has the intermediate activity (Kamal-Eldin and Appelqvist, 1996; Evans et al., 2002). Tocopherol amount is tightly controlled in the photosynthetic membranes to properly regulate the membrane stability. Role of tocopherol in preventing lipid peroxidation has been noticed in many reports. Lipid peroxyl radicals, which are involved in the propagation of lipid peroxidation, are scavenged by tocopherol (Liebler, 1993). It regulates the expression of genes involved in lipid peroxidation (Sattler et al., 2006). Tocopherol deficiency led to an enhancement in the lipid peroxidation in the transgenic tobacco leaves (Abbasi et al., 2009). It was estimated that the one molecule of tocopherol by using resonance energy transfer could degrade 120 singlet oxygen molecules (Fahrenholzt et al., 1974). Hydroperoxydienone intermediates this reaction, which further gives rise to tocopherol quinone and tocopherol quinol epoxides (Murkovic et al., 1997; Kobayashi and Dellapenna, 2008). Oxidized tocopherol can be recycled back to its reduced form. $\alpha$-tocopherol quinone has been shown to convert back to $\alpha$-tocopherol in Arabidopsis thaliana chloroplasts (Kobayashi and Dellapenna, 2008). Interaction between carotenoids and $\alpha$-tocopherol also plays significant role during photooxidative stress in plants. Their interaction was shown to protect the photosystem-II of Chlamydomonas reinhardtii from the damage of singlet oxygen species under herbicides stress (Trebst et al., 2002). In the membranes, tocopherol can form complexes with polyunsaturated fatty acid (PUFA). $\mathrm{OH}^{\bullet}$ oxidizes PUFA and form lipid peroxyl radical from superoxide. Tocopherol gives rise to the formation of lipid hydroperoxide from lipid peroxyl radicals. It is efficient in breaking the chain reactions of free radicals of PUFA produced by lipid peroxidation (Havaux et al., 2005).

Tocopherol works cooperatively with the other antioxidants such as glutathione, ascorbate, carotenoids etc... and helps in the maintenance of appropriate redox state inside the chloroplast under various adverse environmental conditions (Munne-Bosch, 2005). Low molecular weight antioxidants such as tocopherol, glutathione, and ascorbate form a triad and provide protection 


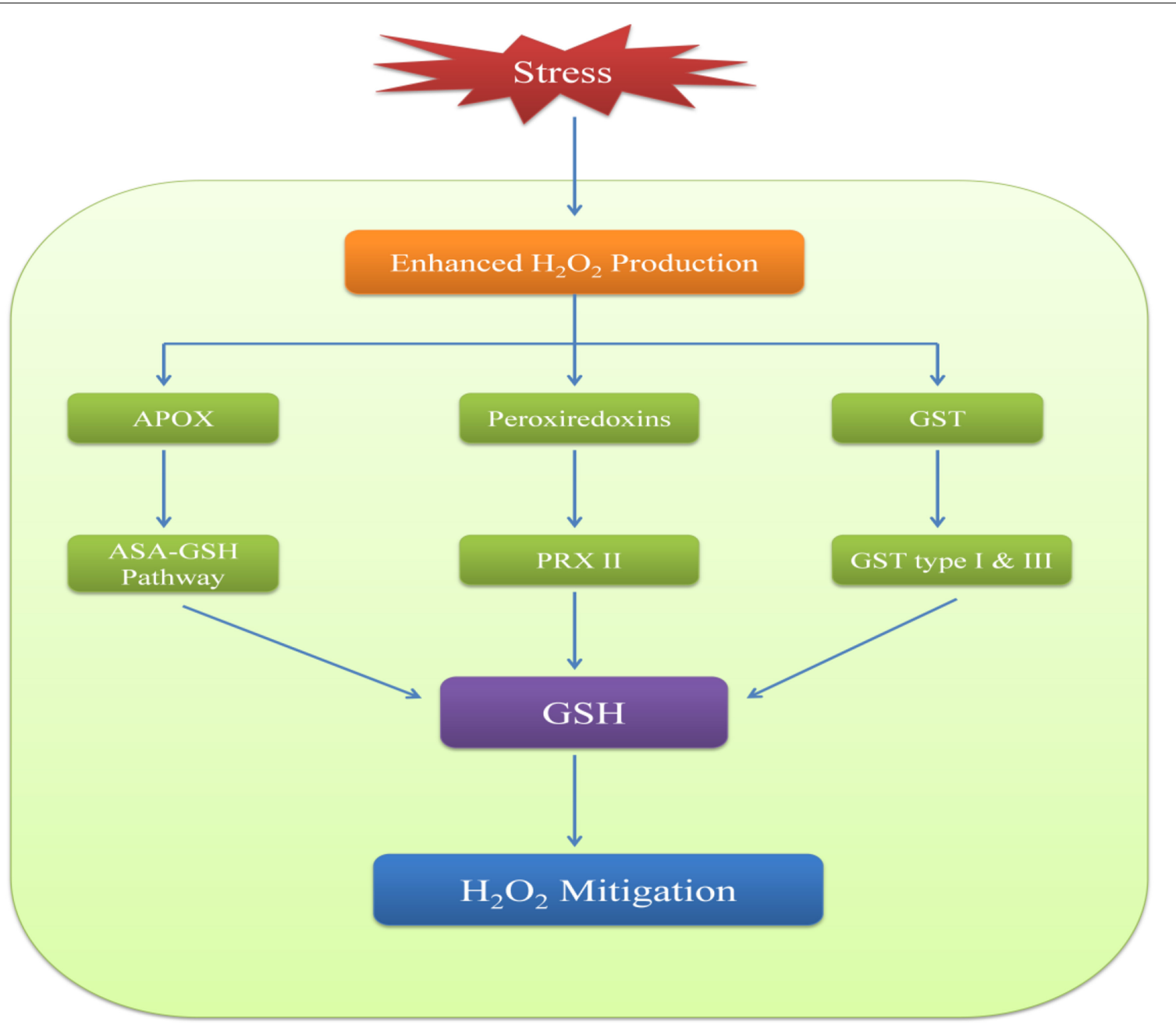

FIGURE 3 | Role of GSH in maintaining $\mathrm{H}_{2} \mathrm{O}_{2}$ homeostasis via APOX, peroxiredoxins and GST.

against abiotic stresses (Szarka et al., 2012). The increase in the amount of these antioxidants can be achieved in two ways i.e., by increasing their biosynthesis or by increasing their biological efficacy by increasing their redox recycling. Their interdependency plays an important role during the electron transfer step inside a cell (Ahmad et al., 2010; Gill and Tuteja, 2010). The increase in the $\alpha$-tocopherol occurred with the increase in the ascorbate content under the conditions of $\mathrm{Cu}$ stress (Collin et al., 2008). Simultaneous loss of glutathione and $\alpha$-tocopherol more severely affected the photosynthetic apparatus stability and efficiency in A. thaliana plants (Kanwischer et al., 2005). Coordinated action of these three antioxidants helps in the maintenance of the redox homeostasis in a more efficient way.

\section{THIOREDOXIN}

Thioredoxins are small $(12-14 \mathrm{kDa})$ and low molecular mass proteins, which are involved in cell redox regulation and are ubiquitously present in all organisms from prokaryotes to eukaryotes (Schurmann and Jacquot, 2000). These were firstly discovered in Escherichia coli as an electron donor for ribonucleotide reductase, an enzyme required for DNA synthesis (Moore, 1967). There are two distinct families (family I and II) of thioredoxin which are distinguished on the basis of their amino acid sequences. Family I includes proteins that consist of one distinct thioredoxin domain, whereas family II is composed of proteins with one or more thioredoxin domains coupled to additional domains (Gelhaye et al., 2004). Plants contain a comprehensive thioredoxin system and it is divided into six major groups: thioredoxin $f, h, m, o, x$, and $y$ on the basis of their sequence and are localized in chloroplast, mitochondria, cytosol and even in the nucleus. Among these thioredoxin $\mathrm{m}, \mathrm{x}$, and $\mathrm{y}$ are related to prokaryotic thioredoxin and $\mathrm{f}, \mathrm{h}$, and $\mathrm{o}$ are specific to eukaryotic organisms (Gelhaye et al., 2005; Collet and Messens, 2010).

Thioredoxin plays important role in plants as they are involved in multiple processes, such as photorespiration, lipid metabolism, membrane transport, hormone metabolism, and ATP synthesis (Balmer et al., 2004). They also play important role against various environmental stresses and also protects proteins from oxidative aggregation and inactivation (Holmgren, 1995). A 
Thioredoxin " $h$ " is required during nodule development to reduce the ROS level in soybean roots (Lee et al., 2005).

Role of mitochondrial thioredoxin PsTrxo1 was reported in providing tolerance against the salt stress (Marti et al., 2011). Plants respond against salinity stress by increasing the mitochondrial thioredoxin activity and protect the mitochondria from oxidative stress by stimulating the activities of antioxidative enzymes. Thioredoxin " $h$ " promote the mobilization of carbon and nitrogen of the endosperm early in grain germination (Wong et al., 2002; Shahpiri et al., 2009). Abiotic stresses elevate thioredoxins either on the gene level or on protein level. Data on proteomics study showed that thioredoxins genes were upregulated in rice under $\mathrm{Cu}$ stress (Song et al., 2013). Genomic study of rice, revealed the significant differences in the gene expression of thioredoxin under biotic and abiotic stress conditions (Nuruzzaman et al., 2012).

Thioredoxins play fundamental role in plant tolerance of oxidative stress. They are involved in combating the oxidative damage by transferring reducing power to reductases for the detoxification of lipid hydroperoxides and thus repairing the oxidized proteins (Santos and Rey, 2006). They scavenge the ROS by modulating the antioxidative enzymes and also involved in oxidative stress associated signaling pathway through the control of glutathione peroxidase (Vivancos et al., 2005). Further Serrato et al. (2004) reported a role of NADPH thioredoxin reductase (NTR) in plant protection against oxidative stress. Deficiency of NTR caused growth inhibition and hypersensitivity in reponse to salinity stress, whereas NTRC knock-out mutant in Arabidopsis expressed the role of thioredoxins against salt stress. Thus, thioredoxins protect the plants from oxidative damage and indicate that thioredoxins involves in antioxidative defense system.

\section{PEROXIREDOXINS}

Peroxiredoxins (Prxs) are a group of antioxidative enzymes including catalase, superoxide dismutase, ascorbate peroxidase, and glutathione peroxidase. These were found firstly in barley plants when genes Hv-1-CysPrx and Hv-2-CysPrx were cloned from the plant (Stacy et al., 1996). Later on it was cloned in various other plants such as Arabidopsis, Oryza sativa, Riccia fluitans, Spinacia oleracea, Populus spp., Nicotiana tabacum and Secale cereal. Prxs show alike structure with basic protein and a thioredoxin fold, and have molecular mass ranging from 17 to $22 \mathrm{kDa}$. On the basis of sequence similarity and catalytic mechanisms Prx proteins are classified into four categories- (a) 1-Cys Prx, (b) Prx II, (c) 2-Cys Prx and (d) PrxQ (Rouhier and Jacquot, 2002, 2005; Dietz, 2003).

Abiotic stresses (drought stress, salinity stress, heavy metals etc...) are the prime threat found these days to the plants due to changing climate and industrial revolution. During abiotic stress, ROS production increases and represents a fundamental problem for the regular metabolism of plants. PrxQ, a type of peroxiredoxins have been identified in photosynthetic cells, and was noted to be participating in protection of plants against ROS (Foyer and Noctor, 2005). Decrease in chlorophyll in PrxQ knockout of $A$. thaliana was observed, suggesting its role in protection of photosynthetic enzymes (Lamkemeyer et al., 2006). The expression profile of four Prx genes were observed under various stresses such as $\mathrm{NaCl}, \mathrm{NaHCO}_{3}, \mathrm{PEG}, \mathrm{CdCl}_{2}$, and abscisic acid in roots, stems and leaves of Tamarix hispida. Enhanced expression of all the ThPrx was reported under both $\mathrm{NaCl}$ and $\mathrm{NaHCO}_{3}$. Temporal and spatial specificity expression patterns were observed under PEG and $\mathrm{CdCl}_{2}$ stress. ABA treatment has showed different expression of ThPrxs, and it point that these Prxs are involved in the ABA signaling pathway (Gao et al., 2012). Genes have been identified and characterized by Vidigal et al. (2013) encoding for Prxs in Vitis vinifera using quantitative real time PCR under irradiance, heat and water stress. Seven vvprx genes were identified, out of which two were more responsive toward water stress, followed by heat stress and without major change under high irradiance. The vvprxII-2, a recognized PrxII was most responsive toward the heat stress. It was targeted in the chloroplasts and thought to be correlated with abscisic aciddependent thermotolerance. Similarly, vvprxIIF was identified and targeted to mitochondria and was responsive to water stress and supposed to involve in drought tolerance through $\mathrm{H}_{2} \mathrm{O}_{2}$ signaling. Guan et al. (2014) tried to investigate the protective role of PrxQ during abiotic stress in Eustoma grandiflorum Shinn. The capacity of biosynthesis of PrxQ was increased in plant by using the overexpression of the PrxQ gene (SsPrxQ) from Suaeda salsa. This SsPrxQ gene was expressed in E. grandiflorum. Enhanced antioxidant activity and thioredoxin dependent peroxidase activity was shown by rPrx proteins. Improved tolerance to salt and high light intensity was also noticed due to overexpression of SsPrxQ. It has been reported that in Chinese cabbage under heat shock and oxidative stress, 2-Cys Prx change its protein structure from a low molecular weight to high molecular weight (Kim et al., 2009). Enhanced tolerance to methyl viologen-mediated oxidative stress and high temperature was observed by the overexpression of At2-cys Prx in potato (Solanum tuberosum) (Kim et al., 2011). It has been observed by Jing et al. (2006) that tolerance to the salt and cold stress improves with the overexpression of PrxQ from S. salsa in A. thaliana. Overexpression of PrxQ in transgenic maize indicated the increased stress tolerance against oxidative stress and fungal diseases (Kiba et al., 2005). Similarly, overexpression of an Arabidopsis 2-Cys Prx in transgenic tall fescue (Festuca arundinacea) showed more resistance against heat and methyl viologen stress in comparison to control plants. In these plants, less electrolyte leakage and thiobarbituric acid-reactive substances (TBARS) were also observed (Kim et al., 2010). A gene VrPrx which encodes for the 2-Cys Prx has been isolated from the mungbean and studied for the antioxidant activity in vitro. Overexpression of VrPrx in transgenic Arabidopsis showed enhanced antioxidant activities and photosynthetic efficiency under abiotic stress (Cho et al., 2012).

\section{GLUTAREDOXIN}

Glutaredoxins (GRX) are omnipresent proteins of approximately 100 amino-acid residues (Fernandes et al., 2005). Glutaredoxins act as redox enzymes to catalyze the reduction of disulfides by using reduced glutathione (GSH) as a cofactor (Holmgren, 1988, 1989; Holmgren and Gleason, 1988). Glutaredoxins get oxidized by substrates, and are reduced non-enzymatically by glutathione. There is no explicit oxidoreductase to reduce glutaredoxins therefore; oxidation of glutathione is required to reduce 
the glutaredoxins. The oxidized glutathione is then renewed by GR and these mechanisms collectively make up the glutathione system (Holmgren and Fernandes, 2004). The line of function of glutaredoxin is analogous to thioredoxin. GRX holds an active center disulfide bond. According to their redox-active center, they are subgrouped in six classes of the CSY[C/S]-, CGFS-, CC-type, and three groups with additional domain of unknown function. The CC-type GRXs are only found in higher plants (Nilsson and Foloppe, 2004). In A. thaliana, about 30 GRX isoforms are discovered whereas 48 are discovered in $O$. sativa $\mathrm{L}$. (Rouhier et al., 2008). GRX operates in antioxidant defense by reducing dehydroascorbate, peroxiredoxins, and methionine sulfoxide reductase. The glutathione/glutaredoxin system is one of the important cellular factors that have been implicated in the regulation of redox homeostasis (Grant, 2001).

GRX can be engineered to attain enhanced oxidative stress tolerance in plants and using the transgenic plants to investigate redox-controlled processes in temperature stress tolerance. Transgenic expression of fern Pteris vittata glutaredoxin PvGrx5 in A. thaliana increases plant tolerance to high temperature stress and reduces oxidative damage to proteins (Sundaram and Rathinasabapathi, 2010). It is observed that homozygous lines expressing PvGRX5 possess considerably better tolerance to high temperature stress than the vector control and wild-type, and this is related to leaf glutaredoxin specific activities. Cheng et al. (2011) reported that Arabidopsis monothiol glutaredoxin, AtGRXS17, is critical for temperature-dependent postembryonic growth and development via modulating auxin response. Further, AtGRXS17 has played role in anti-oxidative stress and thermotolerance in both yeast and plants (Wu et al., 2012). Ectopic expression of Arabidopsis glutaredoxin AtGRXS17 increases thermotolerance in tomato. Ectopic expression of AtGRXS17 in tomato plants reduces photo-oxidation of chlorophyll and decrease oxidative injury of cell membrane systems under heat stress (Wu et al., 2012).

A glutaredoxin gene SlGRX1 regulates plant responses to oxidative, drought and salt stresses in tomato (Guo et al., 2010). A novel cDNA fragment (SlGRX1) from tomato was isolated and characterized. This fragment encoded a protein containing the consensus GRX family domain with a CGFS active site. SIGRX1 was articulated in all places in tomato including root, stem, leaf, and flower. The expression of SIGRX1 could be induced by oxidative, drought, and salt stresses. Enhancement in sensitivity to oxidative and salt stresses with reduced relative chlorophyll content, and decreased tolerance to drought stress with decreased relative water content were observed after applying virus-induced gene silencing of SIGRX1 in tomato. Quite the opposite, resistance of plants to oxidative, drought, and salt stresses increased considerably by over-expression of SIGRX1 in Arabidopsis plants. The study clearly suggested that the glutaredoxin gene SIGRX1 plays an important role in regulating abiotic tolerance against oxidative, drought, and salt stresses. GRXs also attribute to the high tolerance of in Caulobacter crescentus to heavy metals specifically cadmium and chromate (Hu et al., 2005). A GRX of the fern $P$. vittata PvGRX5 is involved in arsenic tolerance (Sundaram and Rathinasabapathi, 2010). It acts as a sensor of oxidative stress mediated by $\mathrm{H}_{2} \mathrm{O}_{2}$ (Song et al., 2002).Glutaredoxin GRXS13 plays a key role in protection against photo-oxidative stress in Arabidopsis as its expression reduces the photo-oxidative stress generated free radicals (Laporte et al., 2012).

\section{NAD/NAD(P)}

Nicotinamide adenine dinucleotide (NAD) and its derivative nicotinamide adenine dinucleotide phosphate (NADP) are pyridine nucleotide coenzymes that act as cardinal metabolites involved in plant cellular redox homeostasis (Hashida et al., 2009). They occur ubiquitously in all living cells (Noctor et al., 2006). These coenzymes occur as redox couples, $\mathrm{NAD}^{+} / \mathrm{NADP}^{+}$ are oxidized forms and there counter reduced forms are NADH/NADPH. The ratio of oxidized to reduced form i.e., $\mathrm{NAD}(\mathrm{P})^{+} / \mathrm{NAD}(\mathrm{P}) \mathrm{H}$ is known as redox state of a cell and is important signal connecting metabolic state of cell and its gene expression (Schafer and Buettner, 2001; Jambunathan et al., 2010). NADH plays central role as electron shuttle between TCA cycle and mitochondrial electron transport chain. $\mathrm{NADP}^{+} / \mathrm{NADPH}$ acts as important energy storage and transferring molecule in light and dark photosynthetic reactions. $\mathrm{NADH}$ and NADPH also act as reducing equivalents in various catabolic and anabolic processes like nucleic acid and lipid synthesis (Potters et al., 2010). Besides their role as cofactors in energy producing and other metabolic reaction they play key role in redox signaling associated with stress and development by modulating both ROS generation and ROS scavanging (Noctor et al., 2006; Hashida et al., 2009). ROS scavenging is also partly maintained by ascorbate-glutathione cycle and $\operatorname{NADP}(\mathrm{H})$ maintains redox flux in this cycle (Noctor et al., 2006). NAD also regulates cellular processes like calcium signaling via NAD derived cyclic ADP-ribose and transcription and microtubule metabolism via deacetylation and/or mono/poly(ADP-ribosy)lation (Hashida et al., 2009).

As, $\mathrm{NAD}(\mathrm{H})$ and $\mathrm{NADP}(\mathrm{H})$ play discrete physiological roles, maintenance of balance between $\mathrm{NAD}(\mathrm{H}) / \mathrm{NADP}(\mathrm{H})$ is essential for cell survival under normal and stress conditions (Takahara et al., 2010). NADP is generated by adenosine triphosphate (ATP) dependent phosphorylation of NAD catalyzed by NAD kinases (NADK). Decline in levels of pyridine nucleotide as caused under stress induces NAPK which in turn increases $\operatorname{NADP}(\mathrm{H})$ levels at expense of $\mathrm{NAD}(\mathrm{H})$ (Grose et al., 2006). In Arabidopsis, oxidative stress caused by stressed environmental conditions induces expression of NADK1 and NADK3 gene (Berrin et al., 2005; Chai et al., 2005).

Biotic and abiotic stresses cause oxidative stress in plants due to over accumulation of ROS. Oxidative stress may cause damage to organelles, lower antioxidant levels, oxidize proteins, DNA nicking, and ultimately leading to cell death. Among various defense responses against ROS is plants is poly(ADPribosyl)ation (PAR) reaction (Ishikawa et al., 2009). PAR is a post-translational protein modification catalyzed by poly(ADPRib)polymerase (PARP) utilizing $\mathrm{NAD}^{+}$and ATP. PARP catalyzes addition of branched polymers of ADP-Rib on a target protein synthesizing a protein-bound poly(ADP-ribose). These PARP proteins confers resistance to oxidative stress by regulating important cellular processes such as DNA synthesis and repair, chromatin synthesis, cell death, and stress responses to 
genotoxic stress (Noctor et al., 2006; Ogawa et al., 2009). One of the early responses toward DNA damage caused due to oxidative stress is activation of PARP (Ame et al., 1999). Plant possesses two PARP genes; parp1 and parp2 are induced under oxidative stress (Block et al., 2005). Level of PARP induced in plants under stress is directly proportional to severity of stress ( $\mathrm{Ha}$ and Snyder, 1999). Since these defense responses like PAR over consumes $\mathrm{NAD}(\mathrm{P})$, they lead to depletion of NAD concentration. Inhibition of PARP alleviates NAD depletion and ATP consumption diminishing cell death and enhanced tolerance to abiotic stresses (Noctor et al., 2006). Silencing of PARP in Arabidopsis and oil seed produced lines that were resistant to broad spectrum of abiotic stresses due to reduce $\mathrm{NAD}^{+}$consumption and alteration in abscisic levels (Block et al., 2005; Vanderauwera et al., 2007).

Nudix (nucleoside diphosphates linked to some moiety X) hydrolases, hydrolyse nucleoside diphosphate derivates. They act house-cleaning enzymes and play role in maintains PAR and $\mathrm{NAD}(\mathrm{H})$ homeostasis (Ge and Xia, 2008). Twenty nine hydrolases have been identified in A. thaliana (Kraszewska, 2008). In A. thaliana overexpression of AtNUDX2 enhanced tolerance toward oxidative stress by hydrolyzation of ADP-ribose thereby maintaining $\mathrm{NAD}^{+}$and ATP levels (Ogawa et al., 2009). Similarly AtNUDT7 is found to play an important role in maintaining redox homeostasis by regulating balance between $\mathrm{NADH}$ and $\mathrm{NAD}^{+}$via modulating $\mathrm{PAR}$ reaction. Thus, it regulates defense/stress signaling and cell death pathways under oxidative stress (Ishikawa et al., 2009; Jambunathan et al., 2010). In conclusion, NAD/NADP are involved in several signaling pathways that are colligative with stress tolerance and defense reactions.

\section{CONCLUSION}

Aerobic life possesses a worldwide characteristics of redox signal transduction honed through evolution to poise information from metabolism and the environment. Information regarding plant health, principally in terms of strength for defense is fulfilled by both oxidants and antioxidants signaling. Between plant cell stress perception and physiological responses, antioxidants play significant role as a signaling compounds as they also possess a vibrant metabolic interface. Redox homeostasis managers set thresholds for apoplastic and cytoplasmic signaling also act as intermediary of the intracellular redox potential.

\section{REFERENCES}

Abbasi, A.-R., Saur, A., Hennig, P., Tschiersch, H., Hajirezaei, M., Hofius, D., et al. (2009). Tocopherol deficiency in transgenic tobacco (Nicotiana tabacum L.) plants leads to accelerated senescence. Plant Cell Environ. 32, 144-157. doi: 10.1111/j.1365-3040.2008.01907.x

Ahmad, P., Jaleel, C. A., Salem, M. A., Nabi, G., and Sharma, S. (2010). Roles of enzymatic and nonenzymatic antioxidants in plants during abiotic stress. Crit. Rev. Biotechnol. 30, 161-175. doi: 10.3109/07388550903524243

Al-Hakimi, A. B. M., and Hamada, A. M. (2011). Ascorbic acid, thiamine or salicylic acid induced changes in some physiological parameters in wheat grown under copper stress. Plant Protect. Sci. 47, 92-98.

Ame, J. C., Rolli, V., Schreiber, V., Niedergang, C., Apiou, F., Decker, P., et al. (1999). PARP-2,anovelmammalian DNAdamage-dependentpoly (ADPribose) polymerase. J. Biol. Chem. 274, 17860-17868. doi: 10.1074/jbc.274.25. 17860
Balmer, Y., Vensel, W. H., Tanaka, C. K., Hurkman, W. J., Gelhaye, E., Rouhier, N., et al. (2004). Thioredoxin links redox to the regulation of fundamental processes of plant mitochondria. Proc. Natl. Acad. Sci. U.S.A. 101, 2642-2647. doi: 10.1073/pnas.0308583101

Berrin, J. G., Pierrugues, O., Brutesco, C., Alonso, B., Montillet, J. L., Roby, D., et al. (2005). Stress induces the expression of AtNADK-1, a gene encoding a $\mathrm{NAD}(\mathrm{H})$ kinase in Arabidopsis thaliana. Mol. Genet. Genomics 273, 10-29. doi: 10.1007/s00438-005-1113-1

Block, M. D., Verduyn, C., De Brouwer, D., and Cornelissen, M. (2005). Poly(ADPribose) polymerase in plants affects energy homeostasis, cell death and stress tolerance. Plant J. 41, 95-96. doi: 10.1111/j.1365-313X.2004.02277.x

Chai, M. F., Chen, Q. J., An, R., Chen, Y. M., Chen, J., and Wang, X. C. (2005). NADK2, an Arabidopsis chloroplastic NAD kinase, plays a vital role in both chloro- phyll synthesis and chloroplast protection. Plant Mol. Biol. 59, 553-564. doi: $10.1007 /$ s11103-005-6802-y

Chen, Z., and Gallie, D. R. (2005). Increasing tolerance to ozone by elevating foliar ascorbic acid confers greater protection against ozone than increasing avoidance. Plant Physiol. 138, 1673-1689. doi: 10.1104/pp.105.062000

Cheng, N. H., Liu, J. Z., Liu, X., Wu, Q., Thompson, S. M., Lin, J., et al. (2011). Arabidopsis monothiol glutaredoxin, AtGRXS17, is critical for temperaturedependent postembryonic growth and development via modulating auxin response. J. Exp. Bot. 63, 503-515. doi: 10.1074/jbc.M110.201707

Cho, C.-W., Chung, E., Heo, J.-E., So, H.-A., Choi, H.-K., Chung, Y. S., et al. (2012). Molecular characterization of a 2-Cys peroxiredoxin induced by abiotic stress in mungbean. Plant Cell Tiss. Organ Cult. 108, 473-484. doi: 10.1007/s11240-0110061-1

Cho, K., Tiwari, S., Agrawal, S. B., Torres, N. L., Agrawal, M., Sarkar, A., et al. (2011). Tropospheric ozone and plants: absorption, responses and consequences. Rev. Environ. Contam. Toxicol. 212, 61-11. doi: 10.1007/978-1-44198453-1_3

Clemens, S. (2006). Evolution and function of phytochelatin synthases. J. Plant Physiol. 163, 319-332. doi: 10.1016/j.jplph.2005.11.010

Cobbett, C., and Goldsbrough, P. (2002). Phytochelatins and metallothioneins: roles in heavy metal detoxification and homeostasis. Annu. Rev. Plant Biol. 53, 159-182. doi: 10.1146/annurev.arplant.53.100301.135154

Collet, J. F., and Messens, J. (2010). Structure, function, and mechanism of thioredoxin proteins. Antioxid. Redox Signal. 13, 1205-1216. doi: 10.1089/ars.2010.3114

Collin, V. C., Eymery, F., Genty, B., Rey, P., and Havaux, M. (2008). Vitamin E is essential for the tolerance of Arabidopsis thaliana to metal-induced oxidative stress. Plant Cell Environ. 31, 244-257. doi: 10.1111/j.1365-3040.2007.01755.x

Debolt, S., Melino, V., and Ford, C. M. (2007). Ascorbate as a biosynthetic precursor in plants. Ann. Bot. 99, 3-8. doi: 10.1093/aob/mcl236

Dietz, K. J. (2003). Plant peroxiredoxins. Annu. Rev. Plant Biol. 54, 93-107. doi: 10.1146/annurev.arplant.54.031902.134934

Dismukes, G. C., Klimov, V. V., Baranov, S. V., Kozlov, Y. N., DasGupta, J., and Tyryshkin, A. (2001). The origin of atmospheric oxygen on earth: the innovation of oxygenic photosynthesis. Proc. Natl. Acad. Sci. U.S.A. 98, 2170-2175. doi: 10.1073/pnas.061514798

Dixon, D. P., Cummins, I., Cole, D. J., and Edwards, R. (1998). Glutathionemediated detoxification systems in plants. Curr. Opin. Plant Biol. 1, 258-266. doi: 10.1016/S1369-5266(98)80114-3

Dixon, D. P., Hawkins, T., Hussey, P. J., and Edwards, R. (2009). Enzyme activities and subcellular localization of members of the Arabidopsis glutathione transferase superfamily. J. Exp. Bot. 60, 1207-1218. doi: 10.1093/jxb/ern365

Dolatabadian, A., Modarres-Sanavy, S. A. M., and Sharifi, M. (2009). Alleviation of water deficit stress effects by foliar application of ascorbic acid on Zea mays L. J. Agron. Crop Sci. 195, 347-355. doi: 10.1111/j.1439-037X.2009.00382.x

Evans, J., Kodali, D., and Addis, P. (2002). Optimal tocopherol concentrations to inhibit soybean oil oxidation. J. Am. Oil Chem. Soc. 79, 47-51. doi: 10.1007/s11746-002-0433-6

Fahrenholzt, S. R., Doleiden, F. H., Tozzolo, A. M., and Lamola, A. A. (1974). On the quenching of singlet oxygen by a-tocopherol. Photochem. Photobiol. 20, 505-519. doi: 10.1111/j.1751-1097.1974.tb06610.x

Falk, J., and Munne-Bosch, S. (2010). Tocochromanol functions in plants: antioxidation and beyond. J. Exp. Bot. 61, 1549-1566. doi: 10.1093/jxb/ erq030

Feng, Z., Pang, J., Nouchi, I., Kobayashi, K., Yamakawa, T., and Zhu, J. (2010). Apoplastic ascorbate contributes to the differential ozone sensitivity in two 
varieties of winter wheat under fully open-air field conditions. Environ. Pollut. 158, 3539-3545. doi: 10.1016/j.envpol.2010.08.019

Fernandes, A. P., Fladvad, M., Berndt, C., Andrésen, C., Lillig, C. H., Neubauer, P., et al. (2005). A novel monothiol glutaredoxin (Grx4) from Escherichia coli can serve as a substrate for thioredoxin reductase. J. Biol. Chem. 280, 24544-24552. doi: 10.1074/jbc.M500678200

Foyer, C. H. (2015). Redox homeostasis: opening up ascorbate transport. Nat. Plants 1:1401. doi: 10.1038/nplants.2014.12

Foyer, C. H., and Noctor, G. (2005). Oxidant and antioxidant signaling in plants: a re-evaluation of the concept of oxidative stress in a physiological context. Plant Cell Environ. 29, 1056-1107. doi: 10.1111/j.1365-3040.2005.01327.x

Foyer, C. H., Trebst, A., and Noctor, G. (2005). "Protective and signalling functions of ascorbate, glutathione and tocopherol in chloroplasts," in Advances in Photosynthesis and Respiration: Photoprotection, Photoinhibition, Gene Regulation, and Environment, eds B. Demmig-Adams and W. W. Adams (Dordrecht: Springer Science Publishers), 241-68.

Gallie, D. R. (2013). The role of l-ascorbic acid recycling in responding to environmental stress and in promoting plant growth. J. Exp. Bot. 63, 695-709. doi: $10.1093 /$ jxb/ers330

Gao, C., Zhang, K., Yang, G., and Wang, Y. (2012). Expression analysis of four peroxiredoxin genes from Tamarix hispida in response to different abiotic stresses and exogenous Abscisic Acid (ABA). Int. J. Mol. Sci. 13, 3751-3764. doi: 10.3390/ijms13033751

Ge, X., and Xia, Y. (2008). The role of AtNUDT7, a Nudix hydrolase, in the plant defense response. Plant Signal. Behav. 3, 119-120. doi: 10.4161/psb.3.2.5019

Gelhaye, E., Rouhier, N., and Jacquot, J. P. (2004). The thioredoxin h system of higher plants. Plant Physiol. Biochem. 42, 265-271. doi: 10.1016/j.plaphy.2004.03.002

Gelhaye, E., Rouhier, N., Navrot, N., and Jacquot, J. P. (2005). The plant thioredoxin system. Cell Mol. Life Sci. 62, 24-35. doi: 10.1007/s00018-004-4296-4

Gest, N., Gautier, H., and Stevens, R. (2013). Ascorbate as seen through plant evolution: the rise of a successful molecule? J. Exp. Bot. 64, 33-53. doi: $10.1093 /$ jxb/ers 297

Gill, S. S., and Tuteja, N. (2010). Reactive oxygen species and antioxidant machinery in abiotic stress tolerance in crop plants. Plant Physiol. Biochem. 48, 909-930. doi: 10.1016/j.plaphy.2010.08.016

Grant, C. M. (2001). Role of the glutathione/glutaredoxin and thioredoxin systems in yeast growth and response to stress conditions. Mol. Microbiol. 39, 533-541. doi: 10.1046/j.1365-2958.2001.02283.x

Green, M. A., and Fry, S. C. (2005). Vitamin C degradation in plant cells via enzymatic hydrolysis of 4-O-oxalyl-L-threonate. Nature 433, 83-87. doi: 10.1038/nature03172

Grill, E., Loffler, S., Winnacker, E. L., and Zenk, M. H. (1989). Phytochelatins, the heavy-metal-binding peptides of plants, are synthesized from glutathione by a specific gamma-glutamylcysteine dipeptidyl transpeptidase (phytochelatin synthase). Proc. Natl. Acad. Sci. U.S.A. 86, 6838-6842. doi: 10.1073/pnas.86. 18.6838

Grose, J. H., Joss, L., Velick, S. F., and Roth, J. R. (2006). Evidence that feedback inhibition of NAD kinase controls responses to oxidative stress. Proc. Natl. Acad. Sci. U.S.A. 103, 7601-7616. doi: 10.1073/pnas.0602494103

Guan, C., Liu, X., Song, X., Wang, G., Ji, J., and Jin, C. (2014). Overexpression of a peroxiredoxin Q gene, SsPrxQ, in Eustoma grandiflorum Shinn enhances its tolerance to salt and high light intensity Mol. Breed. 33, 657-667. doi: 10.1007/s11032-013-9982-1

Guo, Y., Huang, C., Xie, Y., Song, F., and Zhou, X. (2010). A tomato glutaredoxin gene SIGRX1 regulates plant responses to oxidative, drought and salt stresses. Planta 232, 1499-1509. doi: 10.1007/s00425-010-1271-1

Gururani, M. A., Upadhyaya, C. P., Strasser, R. J., Woong, Y. J., and Park, S. W. (2012). Physiological and biochemical responses of transgenic potato plants with altered expression of PSII manganese stabilizing protein. Plant. Physiol. Biochem. 58, 182-194. doi: 10.1016/j.plaphy.2012.07.003

Ha, H. C., and Snyder, S. H. (1999). Poly (ADP-ribose) polymerase is a mediator of necrotic cell death by ATP depletion. Proc. Natl. Acad. Sci. U.S.A. 96, 13978-13982. doi: 10.1073/pnas.96.24.13978

Ha, S. B., Smith, A. P., Howden, R., Dietrich, W. M., Bugg, S., O'Connell, M. J., et al. (1999). Phytochelatin synthase genes from Arabidopsis and the yeast Schizosaccharomyces pombe. Plant Cell 11, 1153-1164.

Halliwell, B., and Gutteridge, J. M. C. (2000). Free Radicals in Biology and Medicine, 4th Edn. Oxford: Oxford University Press.
Hashida, S. N., Takahashi, H., and Uchimiya, H. (2009). The role of NAD biosynthesis in plant development and stress responses. Ann. Bot. 103, 819-824. doi: 10.1093/aob/mcp019

Havaux, M., Eymery, F., Porfirova, S., Rey, P., and Dormann, P. (2005). Vitamin E Protects against Photoinhibition and Photooxidative Stress in Arabidopsis thaliana. Plant Cell. 17, 3451-3469. doi: 10.1105/tpc.105.037036

Hell, R. (1997). Molecular physiology of plant sulfur metabolism. Planta 202, 138-148. doi: 10.1007/s004250050112

Holmgren, A. (1988). Thioredoxin and glutaredoxin: small multi-functional redox proteins with active-site disulfide bonds. Biochem. Soc. Trans. 16, 95-106.

Holmgren, A. (1989). Thioredoxin and glutaredoxin systems. J. Biol. Chem. 264, $13963-13966$

Holmgren, A. (1995). Thioredoxin structure and mechanism: con- formational changes on oxidation of the active-site sulfhy- dryls to a disulfide. Structure 3 , 239-243. doi: 10.1016/S0969-2126(01)00153-8

Holmgren, A., and Fernandes, A. P. (2004). Glutaredoxins: glutathione-dependent redox enzymes with functions far beyond a simple thioredoxin backup system. Antioxid. Redox. Signal. 6, 63-74. doi: 10.1089/152308604771978354

Holmgren, A., and Gleason, F. K. (1988). Thioredoxin and related proteins in procaryotes. FEMS Microbiol. Rev. 4, 271-297.

Hu, P., Brodie, E. L., Suzuki, Y., McAdams, H. H., and Andersen, G. L. (2005). Whole-genome transcriptional analysis of heavy metal stresses in Caulobacter crescentus. J. Bacteriol. 187, 8437-8449. doi: 10.1128/JB.187.24.8437-8449.2005

Iqbal, A., Yabuta, Y., Takeda, T., Nakano, Y., and Shigeoka, S. (2006). Hydroperoxide reduction by thioredoxin-specific glutathione peroxidase isoenzymes of Arabidopsis thaliana. FEBS J. 273, 5589-5597. doi: 10.1111/j.17424658.2006.05548.x

Ishikawa, K., Ogawa, T., Hirosue, E., Nakayama, Y., Harada, K., Fukusaki, E., et al. (2009). Modulation of the poly(ADP-ribosyl)ation reaction via the Arabidopsis ADP-Ribose/NADH pyrophosphohydrolase, AtNUDX7, is involved in the response to oxidative stress. Plant Physiol. 151, 741-754. doi: 10.1104/pp.109.140442

Ishikawa, T., Dowdle, J., and Smirnoff, N. (2006). Progress in manipulating ascorbic acid biosynthesis and accumulation in plants. Physiol. Plant 126, 343-355. doi: 10.1111/j.1399-3054.2006.00640.x

Jambunathan, N., Penaganti, A., Tang, Y., and Mahalingam, R. (2010). Modulation of redox homeostasis under suboptimal conditions by Arabidopsis nudix hydrolase 7. BMC Plant Biol. 10:173. doi: 10.1186/1471-2229-10-173

Jimenez, A., Hernandez, J. A., Pastori, G., del Rio, L. A., and Sevilla, F. (1998). Role of the ascorbate-glutathione cycle of mitochondria and peroxisomes in the senescence of pea leaves. Plant Physiol. 118, 1327-1335. doi: 10.1104/pp.118.4.1327

Jing, L. W., Chen, S. H., Guo, X. L., Zhang, H., and Zhao, Y. X. (2006) Overexpression of a chloroplast-located peroxiredoxin Q gene, SsPrxQ, increases the salt and low-temperature tolerance of Arabidopsis. J. Integr. Plant Biol. 48, 1244-1249. doi: 10.1111/j.1744-7909.2006.00357.x

Kamal-Eldin, A., and Appelqvist, L. A. (1996). The chemistry and antioxidant properties of tocopherols and tocotrienols. Lipids 31, 671-701. doi: 10.1007/BF02522884

Kanwischer, M., Porfirova, S., Bergmuller, E., and Dormann, P. (2005). Alterations in tocopherol cyclase activity in transgenic and mutant plants of Arabidopsis affect tocopherol content, tocopherol composition and oxidative stress. Plant Physiol. 137, 713-723. doi: 10.1104/pp.104.054908

Karuppanapandian, T., and Manoharan, K. (2008). Uptake and translocation of tri- and hexa-valent chromium and their effects on black gram (Vigna mungo L. Hepper cv. Co4) roots. J. Plant Biol. 51, 192-201. doi: 10.1007/BF03 030698

Karuppanapandian, T., Wang, H. W., Prabakaran, N., Jeyalakshmi, K., Kwon, M., Manoharan, K., et al. (2011). 2,4-dichlorophenoxyacetic acid-induced leaf senescence in mung bean (Vigna radiata L. Wilczek) and senescence inhibition by co-treatment with silver nanoparticles. Plant Physiol. Biochem. 49, 168-177. doi: 10.1016/j.plaphy.2010.11.007

Khan, T. A., Mazid, M., and Mohammad, F. (2011). A review of ascorbic acid potentialities against oxidative stress induced in plants. J. Agrobiol. 28, 97-11. doi: 10.2478/v10146-011-0011-x

Kiba, A., Nishihara, M., Tsukatani, N., Nakatsuka, T., Kato, Y., and Yamamura, S. (2005). A peroxiredoxin $\mathrm{Q}$ homolog from gentians is involved in both resistance against fungal disease and oxidative stress. Plant Cell Physiol. 46, 1007-1015. doi: 10.1093/pcp/pci109 
Kim, K. H., Alam, I., Lee, K. W., Sharmin, S. A., Kwak, S. S., Lee, S. Y., et al. (2010). Enhanced tolerance of transgenic tall fescue plants overexpressing 2-Cys peroxiredoxin against methyl viologen and heat stresses. Biotechnol. Lett. 32, 571-576. doi: 10.1007/s10529-009-0185-0

Kim, M. D., Kim, Y. H., Kwon, S. Y., Jang, B. Y., Lee, S. Y., Yun, D. J., et al. (2011). Overexpression of 2-cysteine peroxiredoxin enhances tolerance to methyl viologen-mediated oxidative stress and high temperature in potato plants. Plant Physiol. Biochem. 49, 891-897. doi: 10.1016/j.plaphy.2011.04.001

Kim, S. Y., Jang, H. H., Lee, J. R., Sung, N. R., Lee, H. B., Lee, D. H., et al. (2009). Oligomerization and chaperone activity of a plant 2-Cys peroxiredoxin in response to oxidative stress. Plant Sci. 177, 227-232. doi: 10.1016/j.plantsci.2009.05.010

Kobayashi, N., and Dellapenna, D. (2008). Tocopherol metabolism, oxidation and recycling under high light stress in Arabidopsis. Plant J. 55, 607-618. doi: 10.1111/j.1365-313X.2008.03539.x

Koussevitzky, S., Suzuki, N., Huntington, S., Armijo, L., Sha, W., Cortes, D., et al. (2008). Ascorbate peroxidase 1 plays a key role in the response of Arabidopsis thaliana to stress combination. J. Biol. Chem. 283, 34197-34203. doi: 10.1074/jbc.M806337200

Kraszewska, E. (2008). The plant Nudix hydrolase family. Acta Biochim. Pol. 55, 663-671.

Lamkemeyer, P., Laxa, M., Collin, V., Li, W., Finkemeier, I., Schöttler, M. A., et al. (2006). Peroxiredoxin Q of Arabidopsis thaliana is attached to the thylakoids and functions in context of photosynthesis. Plant J. 45, 968-981. doi: 10.1111/j.1365-313X.2006.02665.x

Laporte, D., Olate, E., Salinas, P., Salazar, M., Jordana, X., and Holuigue, L. (2012). Glutaredoxin GRXS13 plays a key role in protection against photooxidative stress in Arabidopsis. J. Biol. Chem. 286, 20398-20406. doi: 10.1093/jxb/err301

Lazzarotto, F., Teixeira, F. K., Rosa, S. B., Dunand, C., Fernandes, C. L., Fontenele Ade, V., et al. (2011). Ascorbate peroxidase-related (APx-R) is a new heme-containing protein functionally associated with ascorbate peroxidase but evolutionarily divergent. New Phytol. 191, 234-250. doi: 10.1111/j.14698137.2011.03659.x

Lee, M., Shin, K., Kim, Y., Suh, J., Gu, Y. Y., Kim, M. R., et al. (2005). Induction of Thioredoxin is required for nodule development to reduce reactive oxygen species levels in soybean roots. Plant Physiol. 139, 1881-1889. doi: 10.1104/pp. 105.067884

Lee, S. H., Ahsan, N., Lee, K. W., Kim, D. H., Lee, D. G., Kwak, S. S., et al. (2007). Simultaneous overexpression of both CuZn superoxide dismutase and ascorbate peroxidase in transgenic tall fescue plants confers increased tolerance to a wide range of abiotic stresses. J. Plant Physiol. 164, 1626-1638. doi: 10.1016/j.jplph.2007.01.003

Le Martret, B., Poage, M., Shiel, K., Nugent, G. D., and Dix, P. J. (2011). Tobacco chloroplast transformants expressing genes encoding dehydroascorbate reductase, glutathione reductase, and glutathione-S-transferase, exhibit altered antioxidant metabolism and improved abiotic stress tolerance. Plant Biotechnol. J. 9, 661-673. doi: 10.1111/j.1467-7652.2011.00611.x

Li, F., Wu, Q. Y., Sun, Y. L., Wang, L. Y., Yang, X. H., and Meng, Q. W. (2010). Overexpression of chloroplastic monodehydroascorbate reductase enhanced tolerance to temperature and methyl viologen-mediated oxidative stresses. Physiol. Plant. 139, 421-434. doi: 10.1111/j.1399-3054.2010.01369.x

Liebler, D. C. (1993). The role of metabolism in the antioxidant function of vitamin E. Crit. Rev. Toxicol. 23, 147-169. doi: 10.3109/10408449309117115

Lisko, K. A., Aboobucker, S. I., Torres, R., and Lorence, A. (2014). "Engineering elevated vitamin $\mathrm{c}$ in plants to improve their nutritional content, growth, and tolerance to abiotic stress," in Phytochemicals-Biosynthesis, Function and Application, Recent Advances in Phytochemistry, ed R. Jetter (Switzerland: Springer International Publishing), 109-128. doi: 10.1007/978-3-31904045-5_6

Maddison, J., Lyons, T., Plöchl, M., and Barnes, J. (2002). Hydroponically cultivated radish fed L-galactono-1,4-lactone exhibit increased tolerance to ozone. Planta 214, 383-391. doi: 10.1007/s004250100625

Mafakheri, A., Siosemardeh, A., Bahramnejad, B., Struik, P. C., and Sohrabi, Y. (2010). Effect of drought stress on yield, proline and chlorophyll contents in three chickpea cultivars. Aust. J. Crop Sci. 4, 580-585.

Manoharan, K., Karuppanapandian, T., Sinha, P. B., and Prasad, R. (2005). Membrane degradation, accumulation of phosphatidic acid, stimulation of catalase activity and nuclear DNA fragmentation during 2,4-D-induced leaf senescence in mustard. J. Plant Biol. 48, 394-403. doi: 10.1007/BF03030581
Marti., M. C., Florez-Sarasa, I., Camejo, D., Ribas-Carbo, M., Lazaro, J. J., Francisca Sevilla, F., et al. (2011). Response of mitochondrial thioredoxin Ps Trxol, antioxidant enzymes and respiration to salinity in pea (Pisum sativum L.) leaves. J. Exp. Bot. 10, 1093-1097. doi: 10.1093/jxb/err076

Meister, A. (1988). Glutathione metabolism and its selective modification. J. Biol. Chem. 263, 17205-17208.

Mhamdi, A., Hager, J., Chaouch, S., Queval, G., Han, Y., Taconnat, L., et al. (2010). Arabidopsis glutathione reductasel plays a crucial role in leaf responses to intracellular hydrogen peroxide and in ensuring appropriate gene expression through both salicylic acid and jasmonic acid signaling pathways. Plant Physiol. 153, 1144-1160. doi: 10.1104/pp.110.153767

Mittler, R., and Zilinskas, B. A. (1992). Molecular cloning and characterization of a gene encoding pea cytosolic ascorbate peroxidase. J. Biol. Chem. 267, 21802-21807.

Moller, I. M., Jensen, P. E., and Hansson, A. (2007). Oxidative modifications to cellular components in plants. Annu. Rev. Plant Biol. 58, 459-481. doi: 10.1146/annurev.arplant.58.032806.103946

Moore, E. C. (1967). A thioredoxin-thioredox in reductase system from rat tumor. Biochem. Biophys. Res. Commun. 29, 264-268. doi: 10.1016/0006291X(67)90446-9

Müller-Moulé, P. (2008). An expression analysis of the ascorbate biosynthesis enzyme VTC2. Plant Mol. Biol. 68, 31-41. doi: 10.1007/s11103-008-9350-4

Munne-Bosch, S. (2005). The role of a-tocopherol in plant stress tolerance. J. Plant Physiol. 162, 743-748. doi: 10.1016/j.jplph.2005.04.022

Murkovic, M., Wiltschko, D., and Pfannhauser, W. (1997). Formation of alphatocopherolquinone and alpha-tocopherolquinone epoxides in plant oil. Fett 99, 165-169. doi: 10.1002/lipi.19970990504

Najami, N., Janda, T., Barriah, W., Kayam, G., Tal, M., Guy, M., et al. (2008). Ascorbate peroxidase gene family in tomato: its identification and characterization. Mol. Genet. Genomics 279, 171-182. doi: 10.1007/s00438-0070305-2

Navrot, N., Collin, V., Gualberto, J., Gelhaye, E., Hirasawa, M., Rey, P., et al. (2006). Plant glutathione peroxidases are functional peroxiredoxins distributed in several subcellular compartments and regulated during biotic and abiotic stress. Plant Physiol. 142, 1364-1379. doi: 10.1104/pp.106.089458

Navrot, N., Roubier, N., Gelbaye, E., and Jacquot, J.-P. (2007). Reactive oxygen species generation and antioxidant systems in plant mitochondria. Physiol. Plant 129,185-195. doi: 10.1111/j.1399-3054.2006.00777.x

Neubauer, C., and Yamamoto, H. Y. (1992). Mehler-peroxidase reaction mediates zeaxanthin formation and zeaxanthin-related fluorescence quenching in intact chloroplasts. Plant Physiol. 99, 1354-1361.

Nilsson, L., and Foloppe, N. (2004). The glutaredoxin -C-P-Y-C- motif: influence of peripheral residues. Structure 12, 289-300. doi: 10.1104/pp.99.4.1354

Noctor, G., Arisi, A.-C. M., Jouanin, L., Kunert, K. J., Rennenberg, H., and Foyer, C. H. (1998). Glutathione: biosynthesis, metabolism and relationship to stress tolerance explored in transformed plants. J. Exp. Bot. 49, 623-647.

Noctor, G., Mhamdi, A., Chaouch, S., Han, Y., Neukermans, J., Marquez-Garcia, B., et al. (2012). Glutathione in plants: an integrated overview. Plant Cell Environ. 35, 454-484. doi: 10.1111/j.1365-3040.2011.02400.x

Noctor, G., Queval, G., and Gakière, B. (2006). NAD(P) synthesis and pyridine nucleotide cycling in plants and their potential importance in stress conditions. J. Exp. Bot. 57, 1603-1620. doi: 10.1093/jxb/erj202

Noctor, G., Queval, G., Mhamdi, A., Chaouch, S., and Foyer, C. H. (2011) Glutathione, Vol. 9. The Arabidopsis Book. New York, NY: American Society of Plant Biologists.

Nuruzzaman, M., Sharoni, A. M., Satoh, K., Moumeni, A., Venuprasad, R., Serraj, R., et al. (2012). Comprehensive gene expression analysis of the NAC gene family under normal growth conditions, hormone treatment, and drought stress conditions in rice using near-isogenic lines (NILs) generated from crossing Aday selection (drought tolerant) and IR64. Mol. Genetics Genom. 287, 389-410. doi: 10.1007/s00438-012-0686-8

Ogawa, T., Ishikawa, K., Harada, K., Fukusaki, E., Yoshimura, K., and Shigeoka, S. (2009). Overexpression of an ADP-ribose pyrophosphatase, AtNUDX2, confers enhanced tolerance to oxidative stress in Arabidopsis plants. Plant J. 57, 289-301. doi: 10.1111/j.1365-313X.2008.03686.x

Pang, C. H., Li, K., and Wang, B. (2011). Overexpression of SsCHLAPXs confers protection. Plant Physiol. Biochem. 48, 292-300. doi: 10.1111/j.1399-3054.2011. 01515.x 
Potters, G., Horemans, N., and Jansen, M. A. (2010). The cellular redox state in plant stress biology-a charging concept. Plant Physiol. Biochem. 48, 292-300. doi: 10.1016/j.plaphy.2009.12.007

Pulido, P., Spínola, M. C., Kirchsteiger, K., Guinea, M., Pascual, M. B., Sahrawy, M., et al. (2010). Functional analysis of the pathways for 2-Cys peroxiredoxin reduction in Arabidopsis thaliana chloroplasts. J. Exp. Bot. 61, 4043-4054. doi: 10.1093/jxb/erq218

Rizhsky, L., Hallak-Herr, E., Van Breusegem, F., Rachmilevitch, S., Barr, J. E., Rodermel, S., et al. (2002). Double antisense plants lacking ascorbate peroxidise and catalase are less sensitive to oxidative stress than single antisense plants lacking ascorbate peroxidase or catalase. Plant J. 32, 329-342. doi: 10.1046/j.1365-313X.2002.01427.x

Rouhier, N., and Jacquot, J. P. (2002). Plant peroxiredoxins: alternative hydroperoxide scavenging enzymes. Photosynth. Res. 74, 93-97. doi: 10.1023/ A: 1021218932260

Rouhier, N., and Jacquot, J. P. (2005). The plant multigenic family of thiol peroxidases. Free Radical Bio. Med. 38, 1413-1421. doi: 10.1016/j.freeradbiomed.2004. 07.037

Rouhier, N., Koh, C. S., Gelhaye, E., Corbier, C., Favier, F., Didierjean, C., et al. (2008). Redox based anti-oxidant systems in plants: biochemical and structural analyses. Biochim. Biophy. Acta 1780, 1249-1260. doi: 10.1016/j.bbagen.2007. 12.007

Sanchez-Fernandez, R., Fricker, M., Corben, L. B., White, N. S., Sheard, N., Leaver, C. J., et al. (1997). Cell proliferation and hair tip growth in the Arabidopsis root are under mechanistically different forms of redox control. Proc. Natl. Acad. Sci. U.S.A. 94, 2745-2750. doi: 10.1073/pnas.94.6.2745

Sanmartin, M., Drogoudi, P. A., Lyons, T., Pateraki, I., Barnes, J., and Kanellis, A. K. (2003). Overexpression of ascorbate oxidase in the apoplast of transgenic tobacco results in altered ascorbate and glutathione redox states and increased sensitivity to ozone. Planta 216, 918-928.

Sano, S., Tao, S., Endo, Y., Inaba, T., Hossain, M. A., Miyake, C., et al. (2005). Purification and cDNA cloning of chloroplastic monodehydroascorbate reductase from spinach. Biosci. Biotechnol. Biochem. 69, 762-772. doi: 10.1271/bbb.69.762

Santos, V. D., and Rey, P. (2006). Plant thioredoxins are key actors in the oxidative stress response. Trends Plant Sci. 11, 329-334. doi: 10.1016/j.tplants.2006.05.005

Sato, Y., Masuta, Y., Saito, K., Murayama, S., and Ozawa, K. (2011). Enhanced chilling tolerance at the booting stage in rice by transgenic overexpression of the ascorbate peroxidase gene OsAPXa. Plant Cell Rep. 30, 399-406. doi: 10.1007/s00299-010-0985-7

Sattler, S. E., Mene-Saffrane, L., Farmer, E. E., Krischke, M., Muller, M. J., and DellaPenna, D. (2006). Non-enzymatic lipid peroxidation reprograms gene expression and activates defense markers in Arabidopsis tocopherol-deficient mutants. Plant Cell 18, 3706-3720. doi: 10.1105/tpc.106. 044065

Scandalios, J. G. (2005). Oxidative stress: molecular perception and transduction of signals triggering antioxidant gene defenses. Braz. J. Med. Biol. Res. 38, 995-914. doi: 10.1590/S0100-879X2005000700003

Schafer, F. Q., and Buettner, G. R. (2001). Redox environment of the cell as viewed through the redox state of the glutathione disulfide/glutathione couple. Free Radic. Biol. Med. 30, 1191-1112. doi: 10.1016/S0891-5849(01)00480-4

Schurmann, P., and Jacquot, J. P. (2000). Plant thioredoxin system revisted. Ann. Rev. Plant physiol. Plant Mol. Biol. 51, 371-400. doi: 10.1146/annurev.arplant. 51.1.371

Serrato, A. J., Pérez-Ruiz, J. M., Spínola, M. C., and Cejudo, F. J. (2004). A novel NADPH thioredoxin reductase, localized in the chloroplast, which deficiency causes hypersensitivity to abiotic stress in Arabidopsis thaliana. J. Biol. Chem. 279, 43821-43827. doi: 10.1074/jbc.M404696200

Shahpiri, A., Svensson, B., and Finnie, C. (2009). From proteomics to structural studies of cytosolic/mitochondrial-type thioredoxin systems in barley seeds. Mol. Plant. 2, 378-389. doi: 10.1093/mp/ssn096

Smirnoff, N. (1996). The function and metabolism of ascorbic acid in plants. Ann. Biol. 78, 661-669.

Song, J. J., Rhee, J. G., Suntharalingam, M., Walsh, S. A., Spitz, D. R., and Lee, Y. J. (2002). Role of glutaredoxin in metabolic oxidative stress: glutaredoxin as a sensor of oxidative stress mediated by $\mathrm{H}_{2} \mathrm{O}_{2}$. J. Biol. Chem. 277, 46566-46575. doi: 10.1074/jbc.M206826200

Song, Y., Cui, J., Zhang, H., Wang, G., Zhao, F. J., and Shen, Z. (2013). Proteomic analysis of copper stress responses in the roots of two rice (Oryza sativa L.) varieties differing in Cu tolerance. Plant Soil 366, 647-658. doi: 10.1007/s11104012-1458-2

Stacy, R. A., Munthe, E., Steinum, T., Sharma, B., and Aalen, R. B. (1996). A peroxiredoxin antioxidant is encoded by a dormancy related gene, Per1, expressed during late development in the aleurone and embryo of barley grains. Plant Mol. Biol. 31, 1205-1216. doi: 10.1007/BF00040837

Sun, W. H., Duan, M., Li, F., Shu, D. F., Yang, S., and Meng, Q. W. (2010). Overexpression of tomato tAPX gene in tobacco improves tolerance to high or low temperature stress. Biol. Plant. 54, 614-620. doi: 10.1007/s10535-0100111-2

Sundaram, S., and Rathinasabapathi, B. (2010). Transgenic expression of fern Pteris vittata lutaredoxin PvGrx5 in Arabidopsis thaliana increases plant tolerance to high temperature stress and reduces oxidative damage to proteins. Planta 231, 361-369. doi: 10.1007/s00425-009-1055-7

Szarka, A., Tomasskovics, B., and Bánhegyi, G. (2012). The Ascorbate-glutathione$\alpha$-tocopherol triad in abiotic stress response. Int. J. Mol. Sci, 13, 4458-4483. doi: 10.3390/ijms 13044458

Tabatabaei, S. A., and Naghibalghora, S. M. (2013). The effect of salinity stress on germination characteristics and changes of biochemically of sesame seeds. Cercetari Agronomice Moldova 47, 61-68. doi: 10.2478/cerce-2014-0017

Takahara, K., Kasajima, I., Takahashi, H., Hashida, S. N., Itami, T., Onodera, H., et al. (2010). Metabolome and photochemical analysis of rice plants overexpressing arabidopsis nad kinase gene. Plant Physiol. 152, 1863-1873. doi: 10.1104/pp.110.153098

Tang, L., Kwon, S. Y., Kim, S. H., Kim, J. S., Choi, J. S., Cho, K. Y., et al. (2006) Enhanced tolerance of transgenic potato plants expressing both superoxide dismutase and ascorbate peroxidase in chloroplasts against oxidative stress and high temperature. Plant. Cell. Rep. 25, 1380-1386. doi: 10.1007/s00299-0060199-1

Tarrago, L., Laugier, E., Zaffagnini, M., Marchand, C., Le Maréchal, P., Rouhier, N., et al. (2009). Regeneration mechanisms of Arabidopsis thaliana methionine sulfoxide reductases B by glutaredoxins and thioredoxins. J. Biol. Chem. 284, 18963-18971. doi: 10.1074/jbc.M109.015487

Teixeira, F. K., Menezes-Benavente, L., Margis, R., and Margis-Pinheiro, M. J. (2004). Analysis of the molecular evolutionary history of the ascorbate peroxidase gene family: inferences from the rice genome. J. Mol. Evol. 59, 761-770. doi: 10.1007/s00239-004-2666-Z

Tóth, S. Z., Nagy, V., Puthur, J. T., Kovács, L., and Garab, G. (2011). The physiological role of ascorbate as photosystem II electron donor: protection against photoinactivation in heat-stressed leaves. Plant Physiol. 156, 382-392. doi: 10.1104/pp.110.171918

Trebst, A., Depka, B., and Hollander-Czytko, H. (2002). A specific role for tocopherol and of chemical singlet oxygen quenchers in the maintenance of photosystem II structure and function in Chlamydomonas reinhardtii. FEBS Lett. 43, 2157-2162. doi: 10.1016/S0014-5793(02)02526-7

Tripathi, B. N., Bhatt, I., and Dietz, K. J. (2009). Peroxiredoxins: a less studied component of hydrogen peroxide detoxification in photosynthetic organisms. Protoplasma 235, 3-15. doi: 10.1007/s00709-009-0032-0

Ushimaru, T., Nakagawa, T., Fujioka, Y., Daicho, K., Naito, M., Yamauchi, Y., et al. (2006). Transgenic Arabidopsis plants expressing the rice dehydroascorbate reductase gene are resistant to salt stress. J. Plant Physiol. 163, 1179-1184. doi: 10.1016/j.jplph.2005.10.002

Vanderauwera, S., De Block, M., de Steene, N. V., de Cotte, B. V., Metzlaff, M., and Breusegem, F. V. (2007). Silencing of poly(ADP-ribose) polymerase in plants alters abiotic stress signal transduction. Proc. Natl. Acad. Sci. U.S.A. 104, 15150-15155. doi: 10.1073/pnas.0706668104

Vatamaniuk, O. K., Mari, S., Lu, Y. P., and Rea, P. A. (1999). Atpcs1, a phytochelatin synthase from Arabidopsis: isolation and in vitro reconstitution. Proc. Natl. Acad. Sci. U.S.A. 96, 7110-7115. doi: 10.1073/pnas.96.12.7110

Vellosillo, T., Vicente, J., Kulasekaran, S., Hamberg, M., and Castresana, C. (2010) Emerging complexity in reactive oxygen species production and signaling during the response of plants to pathogens. Plant Physiol. 154, 444-448. doi: $10.1104 /$ pp. 110.161273

Venkatesh, J., and Park, S. W. (2014). Role of L-ascorbate in alleviating abiotic stresses in crop plants. Bot. Stud. 55, 38-43. doi: 10.1186/1999-3110-55-38

Vidigal, P., Carvalho, R., Amâncio, S., and Carvalho, L. (2013). Peroxiredoxins are involved in two independent signaling pathways in the abiotic stress protection in Vitis vinifera. Biol. Planta. 57, 675-683. doi: 10.1007/s10535-0130346-9 
Vivancos, A. P., Castillo, E. A., Biteau, B., Nicot, C., Ayte, J., Toledano, M. B., et al. (2005). A cysteine-sulfinic acid in peroxiredoxin regulatesH2O2-sensing by the antioxidant Pap1 pathway. Proc. Natl. Acad. Sci. U.S.A. 102, 8875-8880. doi: 10.1073/pnas.0503251102

Wagner, D., Przybyla, D., Op den Camp, R., Kim, C., Landgraf, F., Lee, K. P., et al. (2004). The genetic basis of singlet oxygeninduced stress responses of Arabidopsis thaliana. Science 306, 1183-1195. doi: 10.1126/science.1103178

Wagner, U., Edwards, R., Dixon, D. P., and Mauch, F. (2002). Probing the diversity of the Arabidopsis glutathione S-transferase gene family. Plant Mol. Biol. 49, 515-532. doi: 10.1023/A:1015557300450

Wang, H. S., Yu, C., Zhu, Z. J., and Yu, X. C. (2011). Overexpression in tobacco of a tomato GMPase gene improves tolerance to both low and high temperature stress by enhancing antioxidation capacity. Plant Cell. Rep. 30, 1029-1040. doi: 10.1007/s00299-011-1009-y

Winkler, B. S. (1992). Unequivocal evidence in support of the non- enzymatic redox coupling between glutathione/glutathione disulphide and ascorbic acid/dehydroascorbic acid. Biochim. Biophys. Acta 1117, 287-290. doi: 10.1016/0304-4165(92)90026-Q

Wong, J. H., Kim, Y. B., Ren, P. H., Cai, N., Cho, M. J., Hedden, P., et al. (2002). Transgenic barley grain overexpressing thioredoxinshows evidence that the starchy endosperms commumicated with the embryo and the aleuorone. Proc. Natl. Acad. Sci. U.S.A. 99, 16325-16330. doi: 10.1073/pnas. 212641999

Wu, Q., Lin, J., Liu, J. Z., Wang, X., Lim, W., Oh, M., et al. (2012). Ectopic expression of Arabidopsis glutaredoxin AtGRXS17 enhances thermotolerance in tomato. Plant. Biotech. J. 10, 945-955. doi: 10.1111/j.1467-7652.2012. 00723.x

Yabuta, Y., Mieda, T., Rapolu, M., Nakamura, A., Motoki, T., Takanori, M., et al. (2007). Light regulation of ascorbate biosynthesis is dependent on the photosynthetic electron transport chain but independent of sugars in Arabidopsis. J. Exp. Bot. 58, 2661-2671. doi: 10.1093/jxb/erm124

Yin, L., Wang, S., Eltayeb, A. E., Uddin, M. I., Yamamoto, Y., Tsuji, W., et al. (2010). Overexpression of dehydroascorbate reductase, but not monodehydroascorbate reductase, confers tolerance to aluminum stress in transgenic tobacco. Planta $231,609-621$.

Zheng, J., Shen, W., He, D. Z., Long, K. B., Madison, L. D., and Dallos, P. (2000). Prestin is the motor protein of cochlear outer hair cells. Nature 405, 149-155. doi: $10.1038 / 35012009$

Conflict of Interest Statement: The authors declare that the research was conducted in the absence of any commercial or financial relationships that could be construed as a potential conflict of interest.

Received: 21 December 2014; accepted: 12 February 2015; published online: 04 March 2015.

Citation: Kapoor D, Sharma R, Handa N, Kaur H, Rattan A, Yadav P, Gautam V, Kaur $R$ and Bhardwaj $R$ (2015) Redox homeostasis in plants under abiotic stress: role of electron carriers, energy metabolism mediators and proteinaceous thiols. Front. Environ. Sci. 3:13. doi: 10.3389/fenvs.2015.00013

This article was submitted to Environmental Toxicology, a section of the journal Frontiers in Environmental Science.

Copyright (c) 2015 Kapoor, Sharma, Handa, Kaur, Rattan, Yadav, Gautam, Kaur and Bhardwaj. This is an open-access article distributed under the terms of the Creative Commons Attribution License (CC BY). The use, distribution or reproduction in other forums is permitted, provided the original author(s) or licensor are credited and that the original publication in this journal is cited, in accordance with accepted academic practice. No use, distribution or reproduction is permitted which does not comply with these terms. 